\title{
Effects of minor Sr addition on solidified structure and mechanical properties of Mg-Y-Cu alloy reinforced by long period ordered structure Sen Zhang ${ }^{1, a}$, Quan Zhou ${ }^{1, b}$ and Hao Zhang ${ }^{1, c}$ \\ ${ }^{1}$ School of Aeronautical Manufacturing Engineering, Nanchang Hangkong University, Nanchang 330063, China \\ a1012601283@qq.com, 'lgclzq@sina.com, ${ }^{c} 1248660274 @ q q . c o m$
}

Keywords: $\mathrm{Sr}, \mathrm{Mg}-\mathrm{Y}-\mathrm{Cu}$ alloy, solidified structure, mechanical properties, long period ordered structure

Abstract. Solidified structure and mechanical properties of $\mathrm{Mg}_{97} \mathrm{Y}_{2} \mathrm{Cu}_{1}$ alloy reinforced by long period ordered structure with $0-0.3 \%$ wt $\mathrm{Sr}$ addition were investigated. The results indicate that the addition of $\mathrm{Sr}$ ranging from $0.1 \%$ to $0.2 \%$, solidified structure of the alloy refines and homogenizes gradually. When the $\mathrm{Sr}$ addition increases to $0.3 \%$, the alloy is over-modified. $\mathrm{Mg}_{17} \mathrm{Sr}_{2}$ phase forms in the alloy with the addition of $0.2 \%$ and $0.3 \%$ Sr. With the increase of Sr addition, supercooling degree and mechanical properties of the alloy increases firstly, and then decreases. After adding $0.2 \% \mathrm{Sr}$ to the alloy, the supercooling degree increases $6.7{ }^{\circ} \mathrm{C}$ in max. Mechanical properties of the alloy with $0.2 \% \mathrm{Sr}$ addition is the best, the tensile strength and elongation of the alloy reach 215 MPa and $9.19 \%$, which are increased by up to $24 \%$ and $58 \%$, respectively, compared with the alloy without $\mathrm{Sr}$ addition.

\section{Introduction}

$\mathrm{Mg}$ alloys offer numerous merits in physical, mechanical and casting properties, such as high specific strength and stiffness, good castability suitable for high pressure die casting, high damping capacity, good thermal and electric conductivity, which have a wide range in traffic, communication, electronics and aerospace fields $[1,2] . \mathrm{Mg}$ alloys reinforced by long-period ordered structure are promising candidates for lightweight structural materials developed recently. As a new kind of reinforced phase in $\mathrm{Mg}$ alloys, the long-period ordered structure can improve mechanical properties greatly [3, 4]. Kawamura et al [5] found that $\mathrm{Mg}_{97} \mathrm{Y}_{2} \mathrm{Cu}_{1}$ cast alloy has an 18R-type long period ordered structure that forms coherently with the $\alpha-\mathrm{Mg}$ matrix during casting.

The modification of microstructure is one of the most important, effective and simple methods for improving the mechanical properties of metallic materials. Sr has been proved to be an effective method for achieving a purposeful alteration of the microstructure of casting ingots, such as grain refinement. So far, Sr has been applied to refine grain of many $\mathrm{Mg}$ alloys. Alireza et al [6] found that $\mathrm{Sr}$ could reduce twining and the dynamically recrystallized grain size of AZ31 alloy, also increase the surface cracking tendency during extrusion. Qiu et al [7] found that the $0.5 \% \mathrm{Sr}$ addition could restrain the formation of $\beta-\mathrm{Mg}_{17} \mathrm{Al}_{12}$ phase in $\mathrm{Mg}-6 \mathrm{Zn}-2 \mathrm{Al}-2 \mathrm{Ca}$ alloy. Yang et al[8] found that the addition of $\mathrm{Sr}$ could refine the grain size of $\mathrm{Mg}-9 \mathrm{Li}-3 \mathrm{Al}$ alloy and lead to the formation of the intermetallic compound. Peng et al [9] found that $\mathrm{Sr}$ could refine the microstructure of $\mathrm{Mg}-\mathrm{Nd}-\mathrm{Zr}$ alloy, and increase the volume fraction of the second phase. However, the refinement effect of $\mathrm{Sr}$ addition on solidified structure of $\mathrm{Mg}-\mathrm{Y}-\mathrm{Cu}$ alloy reinforced by long-period ordered structure is less researched. In this work, the effects of different $\mathrm{Sr}$ addition on solidified structure and mechanical properties of $\mathrm{Mg}_{97} \mathrm{Y}_{2} \mathrm{Cu}_{1}$ alloy were studied. 


\section{Experimental}

$\mathrm{Mg}_{97} \mathrm{Y}_{2} \mathrm{Cu}_{1}$ alloy was employed as the raw material for this study. Four alloys were prepared and their designed compositions are listed in Table 1. The experimental alloys were prepared from pure $\mathrm{Mg}, \mathrm{Mg}-30 \mathrm{Y}$ and $\mathrm{Mg}-30 \mathrm{Cu}$ master alloys. Sr was added with the master alloy of $\mathrm{Mg}-25 \mathrm{Sr}$. The alloy was first melted at $750{ }^{\circ} \mathrm{C}$ and held for 20 min under $\mathrm{CO}_{2}+\mathrm{SF}_{6}$ mixture protection in an electrical resistance furnace using a mild steel crucible, and then the melt was poured into a graphite mold with a diameter of $25 \mathrm{~mm}$, height of $80 \mathrm{~mm}$ and a wall-thickness of $5 \mathrm{~mm}$, which was preheated to the temperature of $180{ }^{\circ} \mathrm{C}$. Effects of different $\mathrm{Sr}$ addition on solidified structure and mechanical properties of $\mathrm{Mg}_{97} \mathrm{Y}_{2} \mathrm{Cu}_{1}$ alloy were studied. Samples of the experimental alloys were etched with a solution of $2 \%$ (volume fraction) nitric acid and ethyl alcohol, and then examined by an Olymous optical microscope and Quanta200 type scanning electron microscope (SEM) equipped with an Oxford energy dispersive spectrometer (EDS). Phases in the experimental alloys were analyzed by X-ray diffractometer (XRD). Samples of around $15 \mathrm{mg}$ were heated in a flowing argon atmosphere from room temperature to $700{ }^{\circ} \mathrm{C}$ for $5 \mathrm{~min}$ before being cooled down to $100^{\circ} \mathrm{C}$. The cooling curves were recorded at a cooling speed of $10^{\circ} \mathrm{C} / \mathrm{min}$.

Table 1 Nominal composition of experimental alloys

\begin{tabular}{ccccc}
\hline Alloy & $w(\mathrm{Y}) / \%$ & $w(\mathrm{Cu}) / \%$ & $w(\mathrm{Sr}) / \%$ & $w(\mathrm{Mg}) / \%$ \\
\hline $\mathrm{Mg}_{97} \mathrm{Y}_{2} \mathrm{Cu}_{1}$ & 6.84 & 2.46 & - & Bal. \\
$\mathrm{Mg}_{97} \mathrm{Y}_{2} \mathrm{Cu}_{1}-0.1 \mathrm{Sr}$ & 6.84 & 2.46 & 0.1 & Bal. \\
$\mathrm{Mg}_{97} \mathrm{Y}_{2} \mathrm{Cu}_{1}-0.2 \mathrm{Sr}$ & 6.84 & 2.46 & 0.2 & Bal. \\
$\mathrm{Mg}_{97} \mathrm{Y}_{2} \mathrm{Cu}_{1}-0.3 \mathrm{Sr}$ & 6.84 & 2.46 & 0.3 & Bal. \\
\hline
\end{tabular}

\section{Results}

Figure 1 and Figure 2 show morphology of primary phase and second phase of the alloy with different $\mathrm{Sr}$ addition. It can be seen that without modification of $\mathrm{Sr}$, coarse equiaxed dendrite and continuous net-worked secondary phase can be normally observed in the alloy. The average grain size is about $300 \mu \mathrm{m}$ and the distribution of the second phase is uneven. The addition of $\mathrm{Sr}$ ranging from $0.1 \%$ to $0.2 \%$, primary grains of the alloy refine gradually. Second phase of the alloy becomes more uniform, and its volume fraction increases. When the addition of $\mathrm{Sr}$ is $0.2 \%$, grain size of the alloy reaches about $100 \mu \mathrm{m}$, and morphology of second phase changes from continuously irregular strip-like shape to discontinuously irregular strip-like shape and fine granule-like shape. When the $\mathrm{Sr}$ addition increases to $0.3 \%$, the alloy is over-modified. The above results indicate that $\mathrm{Sr}$ added to $\mathrm{Mg}_{97} \mathrm{Y}_{2} \mathrm{Cu}_{1}$ alloy can refine and homogenize solidified structure of the alloy.

Figure 3 shows the X-ray diffraction (XRD) patterns of alloy with different Sr addition. It is shown that without or with the addition of $0.1 \% \mathrm{Sr}$ in $\mathrm{Mg}_{97} \mathrm{Y}_{2} \mathrm{Cu}_{1}$ alloy, there are primary $\alpha-\mathrm{Mg}$ and $\mathrm{Mg}_{12} \mathrm{Y}_{1} \mathrm{Cu}_{1}$ phase, furthermore a few of new $\mathrm{Mg}_{17} \mathrm{Sr}_{2}$ phase forms in the alloy with the addition of $0.2 \%$ and $0.3 \% \mathrm{Sr}$.

Figure 4 shows the distribution of Sr element by surface scanning EDS analysis of the alloy with $0.2 \% \mathrm{Sr}$ addition. It can be seen that that majority of $\mathrm{Sr}$ elements are distributed along the grain boundary in second phase, farthing of them are distributed in the matrix. It indicates that $\mathrm{Sr}$ distributing in front of the solid-liquid interface may inhibit the grain growth of the alloy.

Figure 5 shows the cooling curves of the different Sr-modified alloys. The peak temperature 
was taken from the top of each peak. All these characteristic temperatures are summarized in Table 2 . The crystallization temperature $\left(T_{L}\right)$ was taken by the extrapolation method from the rising point of the first exothermic peak. It can be found that after adding $0.1 \%-0.3 \% \mathrm{Sr}, T_{L}$ of the alloy decreases. The supercooling degree $\Delta T$ can be expressed as $\Delta T=T_{m}-T_{L}$, in which $T_{m}$ is the melting temperature of the alloy. It is supposed that $T_{m}$ is unchanged after adding $\mathrm{Sr}$ element. With the increase of $\mathrm{Sr}$ addition, the supercooling degree of the alloy increases firstly, and then decreases. After adding $0.2 \% \mathrm{Sr}$ to the alloy, the supercooling degree increases $6.7{ }^{\circ} \mathrm{C}$ in max. It can also be found that $T_{U}$, the formation temperature of the $\mathrm{Mg}_{12} \mathrm{Y}_{1} \mathrm{Cu}_{1}$ phase, increases from $564{ }^{\circ} \mathrm{C}$ to $581{ }^{\circ} \mathrm{C}$ with $0.1 \% \mathrm{Sr}$ addition. However, $T_{U}$ decreases to $570{ }^{\circ} \mathrm{C}$ with $0.3 \% \mathrm{Sr}$ addition.
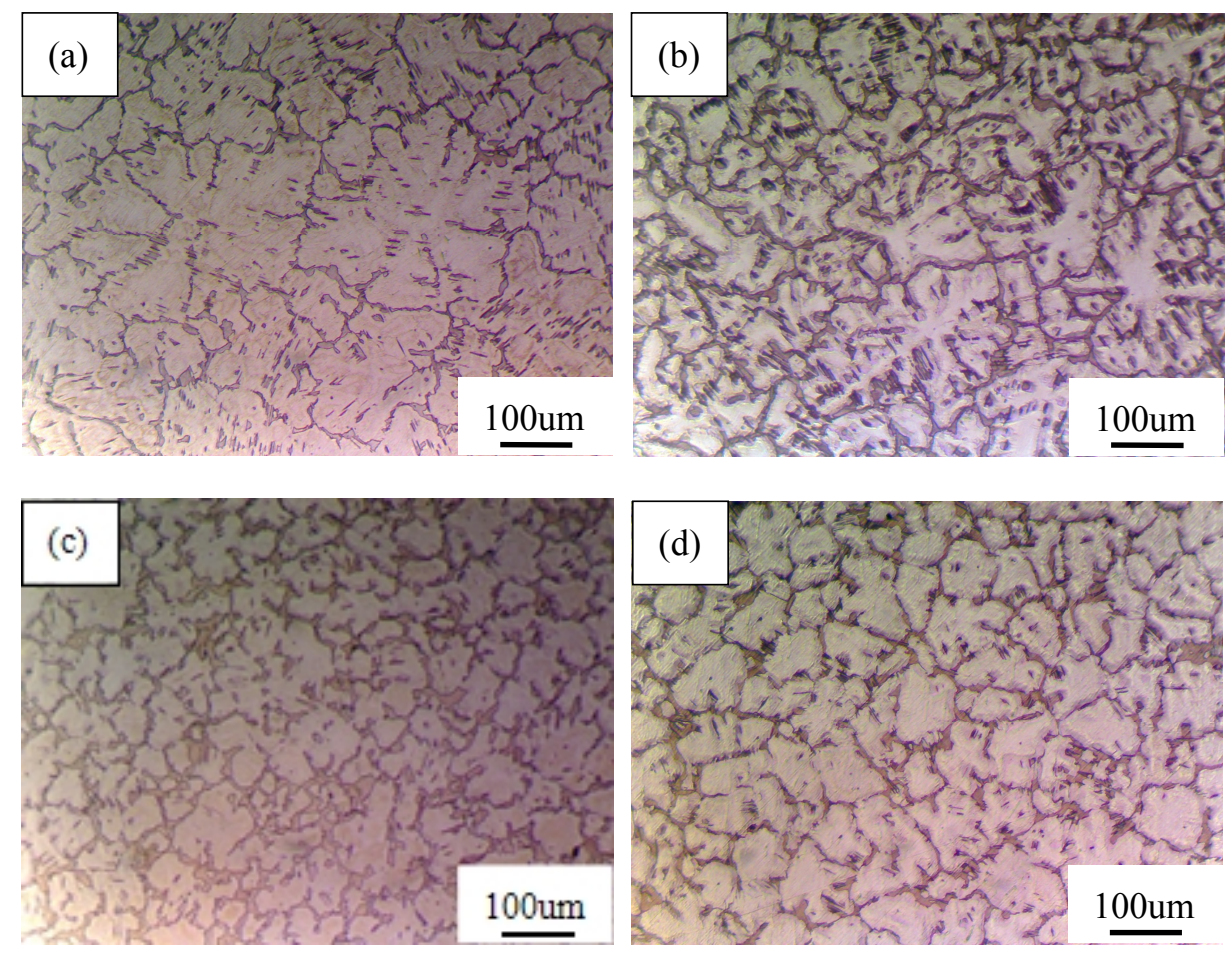

Figure 1 Morphology of primary phase of the alloy with different $\mathrm{Sr}$ addition
(a) $0 \% \mathrm{Sr}$
(b) $0.1 \% \mathrm{Sr}$
(c) $0.2 \% \mathrm{Sr}$
(d) $0.3 \% \mathrm{Sr}$

The effects of different $\mathrm{Sr}$ addition on mechanical properties of the alloy are shown in Fig.5. It is shown that with the increase of the addition of $\mathrm{Sr}$, the mechanical properties of the alloy increases firstly, and then decreases. The mechanical properties of the alloy with $0.2 \% \mathrm{Sr}$ addition is the best, the tensile strength and elongation of the alloy reach $215 \mathrm{MPa}$ and $9.19 \%$, which are increased by up to $24 \%$ and $58 \%$, respectively, compared with the alloy without $\mathrm{Sr}$ addition.

The fracture morphologies of the alloy without and with $0.2 \% \mathrm{Sr}$ addition are shown in Fig.7. It is clear that without $\mathrm{Sr}$ addition treatment, the alloy exhibits the brittle batten feature, which is the typical quasi cleavage fracture. Comparatively, crystalline fining grain can restrain the cleavage fracture. There are many irregular distribution tear ridge in the fracture of sample with $0.2 \% \mathrm{Sr}$ addition, the number of brittle batten decreases obviously and the number of dimple increases evidently, which is also quasi cleavage fracture.

\section{Discussion}

It is well know that the nucleation and grain growth are the main influencing factors to determine the final grain size of the alloy. The effect of $\mathrm{Sr}$ addition on the $\alpha-\mathrm{Mg}$ phase of 
$\mathrm{Mg}_{97} \mathrm{Y}_{2} \mathrm{Cu}_{1}$ alloy can be explained on the basis of growth restriction factor (GRF) [10].

$$
\mathrm{GRF}=\sum_{i} m_{i} c_{0, \quad \mathrm{i}}\left(k_{i}-1\right)
$$

Where, $m_{\mathrm{i}}$ is the slope of the liquidus line in the binary phase diagram, $c_{0, \mathrm{i}}$ is the initial concentration of component $i$, and $k_{\mathrm{i}}$ is the equilibrium partition coefficient of component. In general, GRF represents the ability to inhibit grain growth. The greater the value of GRF is, the stronger its ability is to inhibit grain growth. It can be seen that the GRF value increases with $\mathrm{Sr}$ content. Accordingly, the grain growth is inhibited with the increase of Sr addition, realizing the goal of grain refinement. In addition, $\mathrm{Sr}$, as the surface activity element, is similar to Ca with strong segregation ability in the melt. It forms the intensive constitutional undercooling in a diffusion layer ahead of the advancing solid/liquid interface, which also restricts grain growth and promotes nucleation.
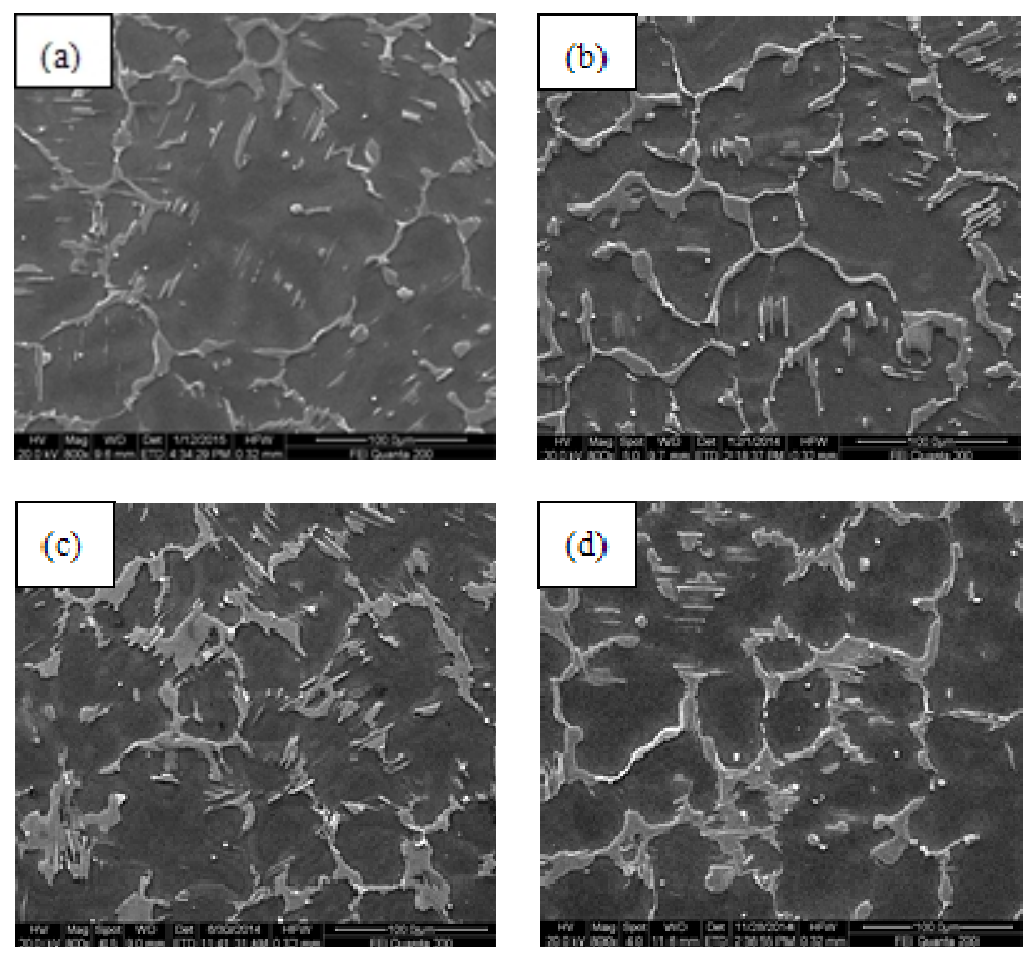

Figure $2 \mathrm{SEM}$ images of the alloy with different $\mathrm{Sr}$ addition
(a) $0 \% \mathrm{Sr}$
(b) $0.1 \% \mathrm{Sr}$
(c) $0.2 \% \mathrm{Sr}$
(d) $0.3 \% \mathrm{Sr}$

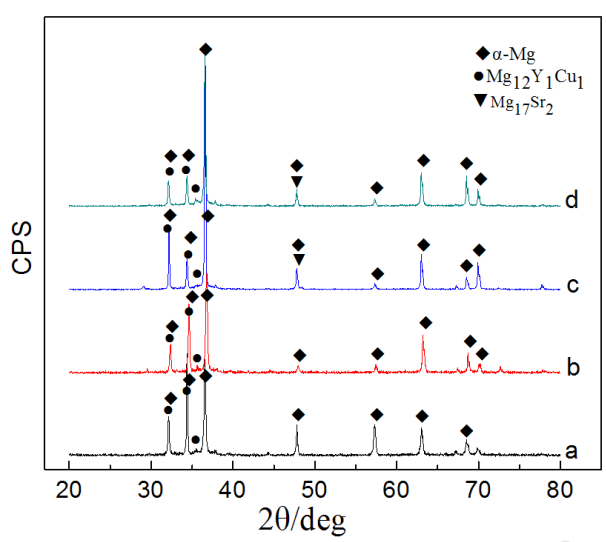

Figure $3 \mathrm{XRD}$ patterns of the alloy with different $\mathrm{Sr}$ addition
(a) $0 \% \mathrm{Sr}$
(b) $0.1 \% \mathrm{Sr}$
(c) $0.2 \% \mathrm{Sr}$
(d) $0.3 \% \mathrm{Sr}$

During the solidification process, the added Sr increases the supercooling degree of the alloy. 
According to the classical nucleation theory, the relationship between critical nucleation radius and supercooling degree is expressed as Eq.2 [11].

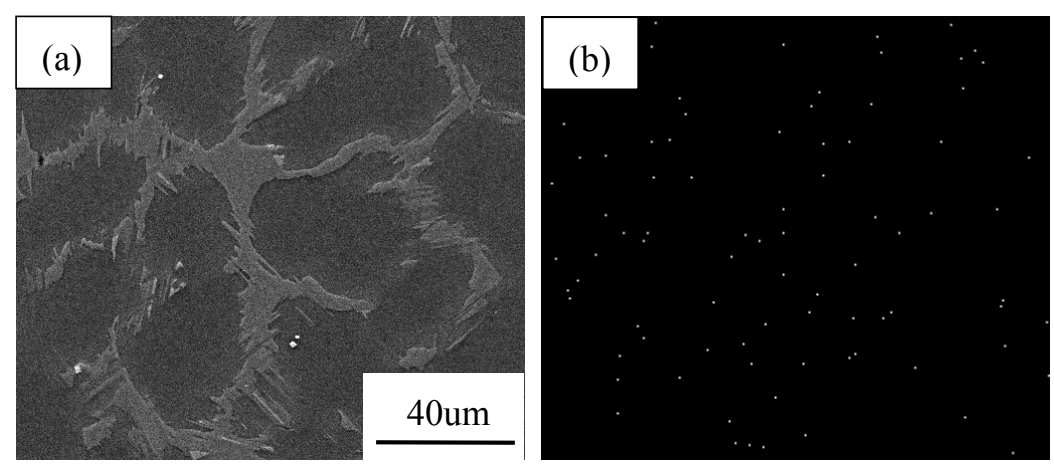

Figure 4 Distribution of Sr element in the alloy with $0.2 \% \mathrm{Sr}$ addition

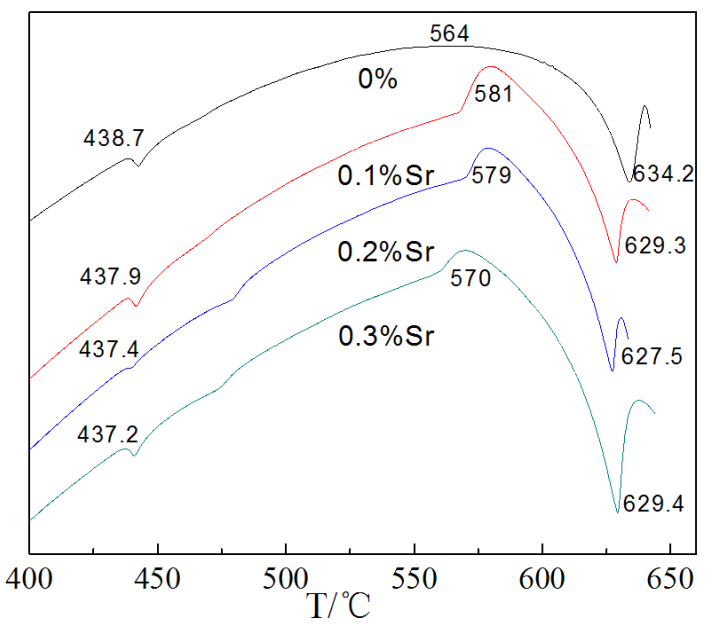

Figure 5 DSC cooling curves of the alloy modified with different $\mathrm{Sr}$ addition
(a) $0 \% \mathrm{Sr}$
(b) $0.1 \% \mathrm{Sr}$
(c) $0.2 \% \mathrm{Sr}$
(d) $0.3 \% \mathrm{Sr}$

Table 2 Characteristic temperature of experimental alloys in DSC cooling curves

\begin{tabular}{ccccc}
\hline Alloy & $\mathrm{T}_{\mathrm{E}} /{ }^{\circ} \mathrm{C}$ & $\mathrm{T}_{\mathrm{U}} /{ }^{\circ} \mathrm{C}$ & $\mathrm{T}_{\mathrm{L}} /{ }^{\circ} \mathrm{C}$ & $\Delta \mathrm{T} /{ }^{\circ} \mathrm{C}$ \\
\hline $\mathrm{Mg}_{97} \mathrm{Y}_{2} \mathrm{Cu}_{1}$ & 438.7 & 564 & 634.2 & 0 \\
$\mathrm{Mg}_{97} \mathrm{Y}_{2} \mathrm{Cu}_{1}-0.1 \mathrm{Sr}$ & 437.9 & 581 & 629.3 & 4.9 \\
$\mathrm{Mg}_{97} \mathrm{Y}_{2} \mathrm{Cu}_{1}-0.2 \mathrm{Sr}$ & 437.4 & 579 & 627.5 & 6.7 \\
$\mathrm{Mg}_{97} \mathrm{Y}_{2} \mathrm{Cu}_{1}-0.3 \mathrm{Sr}$ & 437.2 & 570 & 629.4 & 4.8 \\
\hline
\end{tabular}




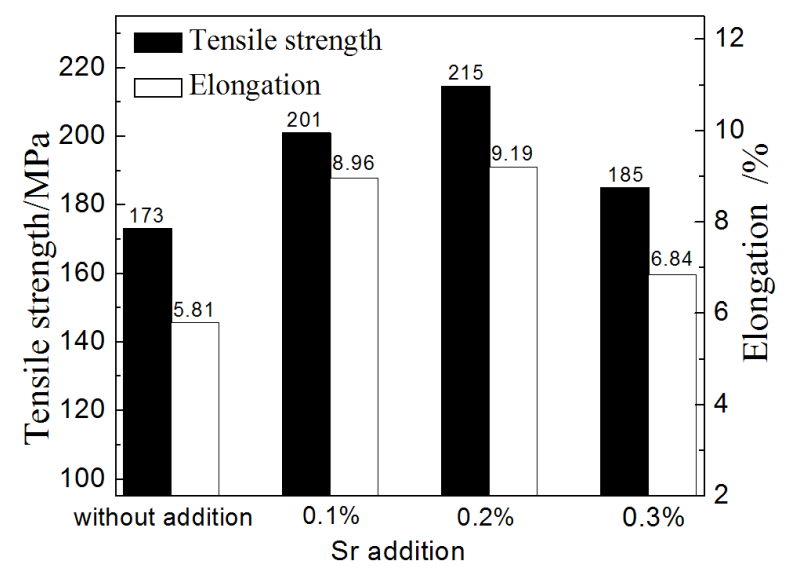

Figure 6 Effect of Sr addition on mechanical properties of the alloy
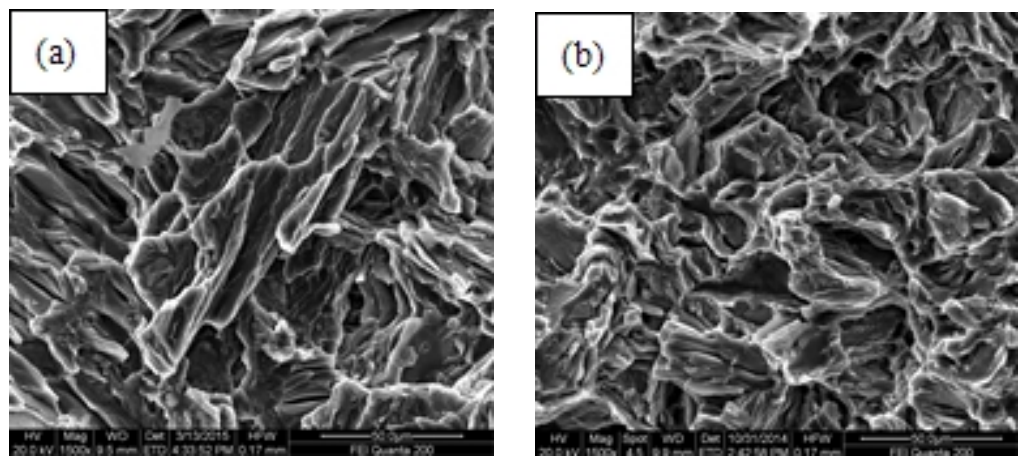

Figure 7 SEM images of fractographs of the alloy

(a) $0 \% \mathrm{Sr}$ (b) $0.2 \% \mathrm{Sr}$

$r_{\mathrm{k}}=\frac{2 \sigma \mathrm{T}_{\mathrm{m}}}{\mathrm{L}_{\mathrm{m}} \cdot \Delta T}$

Where, $\sigma$ is embryos per unit area of surface energy, $L_{m}$ is the crystal latent heat, in which parameters are all pre-determined. Under the given identical solidification condition (i.e cooling rate), the nucleation ratio mainly depends on the supercooling degree of the alloy. Generally, the higher the supercooling degree of the alloy is, the less the critical nucleation radius in the melt is. In this study, the increase of the supercooling degree induces the decrease of the critical nucleation radius in the alloy modified by $\mathrm{Sr}$ addition under the identical solidification condition. With increasing $\mathrm{Sr}$ addition from $0.1 \%$ to $0.2 \%$, the supercooling degree increases, and the restriction on grain growth and the promotion on nucleation become more apparent. The grain size of $\alpha-\mathrm{Mg}$ matrix decreases from $300 \mu \mathrm{m}$ to $100 \mu \mathrm{m}$. With $0.3 \% \mathrm{Sr}$ addition, the supercooling degree of the alloy decreases, so grains of the alloy coarsen.

Second phase of the alloy is mainly formed on the grain boundary of $\alpha-\mathrm{Mg}$ matrix, so fine and uniform crystal is favorable to the morphology and distribution of second phase. After added more than $0.3 \% \mathrm{Sr}$, primary grains coarsen, so homogeneity of second phase decreases.

Grain boundary strengthening presented by the well-known hall-petch relation, is an established method of increasing the yield stress and is the main contributor to the improved mechanical properties. Grain refinement is an important factor to improve the mechanical properties of $\mathrm{Mg}_{97} \mathrm{Y}_{2} \mathrm{Cu}_{1}$ alloy in this experiment. When the addition of $\mathrm{Sr}$ is at $0 \sim 0.2 \%$, with the increase of the addition of Sr, grain size of alloy decreases, so the tensile strength and elongation of the alloy increase. When the addition of $\mathrm{Sr}$ reaches $0.3 \%$, the tensile strength and elongation of the alloy decrease because of grain coarsening. In addition, the morphology and distribution of second phase 
also play an important factor to the improvement of mechanical properties of the alloy, because $\mathrm{Mg}_{97} \mathrm{Y}_{2} \mathrm{Cu}_{1}$ alloy is reinforced by long-period ordered structure. After added Sr treatment, second phase of the alloy becomes more uniform, its volume fraction increases, which is also beneficial to mechanical properties of the alloy.

\section{Conclusions}

1) The addition of $\mathrm{Sr}$ ranging from $0.1 \%$ to $0.2 \%$, solidified structure of the alloy refines and homogenizes gradually. When the $\mathrm{Sr}$ addition increases to $0.3 \%$, the alloy is over-modified. $\mathrm{Mg}_{17} \mathrm{Sr}_{2}$ phase forms in the alloy with additions of $0.2 \%$ and $0.3 \% \mathrm{Sr}$.

2) With the increase of $\mathrm{Sr}$ addition, supercooling degree and mechanical properties of the alloy increases firstly, and then decreases. After adding $0.2 \% \mathrm{Sr}$ to the alloy, the supercooling degree increases $6.7^{\circ} \mathrm{C}$ in max. Mechanical properties of the alloy with $0.2 \% \mathrm{Sr}$ addition is the best, the tensile strength and elongation of the alloy reach $215 \mathrm{MPa}$ and $9.19 \%$, which are increased by up to $24 \%$ and $58 \%$, respectively, compared with the alloy without $\mathrm{Sr}$ addition.

\section{Acknowledgements}

This work was financially supported by the National Natural Science Foundation Project (51261026).

\section{References}

[1] Y.Kojima, T.Aizawa and S.Kamada: Materials Science Forum Vol. 419-422 (2003), P. 3

[2] K.Hazeli, A.Sadeghi, M.O.Pekguleryuz and A.Kontsos: Materials Science and Engineering A Vol. 578(2013), P.383-393

[3] Y.Kawamura, K.Hayashi and A.Inoue: Mater Trans JIM Vol. 42 (2001), P. 1171

[4] W.Wang, H.Zhang, Z.D.Wang: Chinese Journal of Raremetals Vol.38 (2014), P.138-145(In Chinese)

[5] Y. Kawamura, T. Morisaka and S. Izumi: Scripta Mater. Vol. 55 (2006), P. 453-456

[6] A.Sadeghi, M.Hoseini and M.Pekguleryuz: Materials Science and Engineering A Vol. 544(2012), P.70-79

[7] K.Q.Qiu, W.G.Zhang, Y.L.Ren and J.H.You: Material Sciences Vol. 2(2012), P.47-51(In Chinese)

[8] Y.Yang, X.D.Peng, H.M.Wen and B.L.Zheng: Metallurgical and Materials Transactions A Vol. 44A (2013), P. 1101-1113

[9] B.Peng, X.B.Zhang and Z.Z.Wang: Heat Treatment of Metals Vol. 39(2014), P. 41-44(In Chinese)

[10] T.C.Xu, X.D.Peng, J.W.Jiang and W.D.Xie: Trans. Transactions of Nonferrous Metals Society of China Vol. 24(2014), P. 2752-2760

[11]R.J.Cheng, J.Shan, Q.Li and W.J.Liu: Functional materials Vol. 45(2014), P. 5070-5073(In Chinese) 